Original Research Paper

\title{
Subsidence Inferred from a Time Lapse Reservoir Study in a Niger Delta Field, Nigeria
}

\author{
Chukwuemeka Ngozi Ehirim and Tamunonengiyeofori Dagogo \\ Geophysics Research Group, Department of Physics, \\ University of Port Harcourt, P.O. Box 122, Choba, Port Harcourt, Nigeria
}

\author{
Article history \\ Received: 19-08-2016 \\ Revised: $19-10-2016$ \\ Accepted: 24-10-2016 \\ Corresponding Author: \\ Chukwuemeka Ngozi Ehirim \\ Geophysics Research Group, \\ Department of Physics, \\ University of Port Harcourt, \\ P.O. Box 122, Choba, Port \\ Harcourt, Nigeria \\ Email: emekabridgy@yahoo.com
}

\begin{abstract}
Production-induced subsidence due to compressibility and fluid property changes in a Niger delta field has been investigated using well log and 4D seismic data sets. The objective of the study is to evaluate changes in time lapse seismic attributes due to hydrocarbon production and infer to probable ground subsidence. Petrophysical modeling and analysis of well data revealed that Density $(\rho)$, Lambda rho $(\lambda \rho)$ and Acoustic impedance (Ip) are highly responsive to changes in reservoir properties. These properties and water saturation attribute were subsequently, extracted from time-lapse seismic volumes in the immediate vicinity of well locations. Result show that monitor horizon slices exhibit appreciable increases in $\rho$, $\lambda \rho$, Ip and water saturation values compared to the base data, especially around the well locations. These increases in relative values of rock/attribute properties between the time-lapse surveys for a constant overburden stress are obvious indications of pore pressure and fluid depletion in the reservoir. Depletion in these properties increases the effective stress (pressure) and the grain-to-grain contact of the reservoir matrix, with a corresponding decrease in compressibility. Consequently, pore and matrix volume decreases, the reservoir compacts and the ground subsides. However, this is suspected to be small and at the reservoir scale due to low initial reservoir porosity and the relatively large lateral dimension compared to the thickness of the reservoir.
\end{abstract}

Keywords: Hydrocarbon Production, Reservoir Compaction, Subsidence, Pressure Depletion, Saturation Change and 4-D Effect

\section{Introduction}

As the demand for hydrocarbons continue to rise astronomically globally due to technology and population, tertiary recovery methods have been developed and advanced for poorly producing reservoirs, while already producing reservoirs are subjected to increasing pressure to meet global demand. These undoubtedly, will affect the effective stress (pressure) regime on the reservoir and adjacent formations and consequently, impact on reservoir saturation, pressure, structure, geometry and compressibility properties (Hermansen et al., 2000; Gambolati and Teatini, 2015).

The production of hydrocarbon is associated with the deformation and displacement of the ground surface with attendant environmental and socio-economic impacts. Hydrocarbon withdrawal is accompanied with pore pressure and fluid depletion. These increases the effective stress on the grain structure of the reservoir, since the overburden stress (pressure) remains unchanged. Consequently, the reservoir compacts resulting in changes in bulk volume, pre-existing faults are reactivated and surficial subsidence is induced (Segall, 1989; Civasso, 1992; Rutledge et al., 1998; Dyer et al., 1999; Scot et al., 2000; Chan et al., 2007).

Surface subsidence is a small magnitude and high frequency seismic event and perhaps the most wide spread and threatening environmental consequence of hydrocarbon withdrawal. Their spatial and temporal development depends on the production rate, time of production, fluid property, reservoir physical properties and the characteristics of overburden strata (Gaia and Stefano, 2006).

The first reported case of ground subsidence caused by fluid withdrawal was by Fuller (1908). Fuller noted that subsidence was caused by the removal of hydrostatic support due to fluid pressure depletion in a porous media. Pratt and Johnson (1926) collaborated fuller's report by suggesting that subsidence was due to the extraction of gas, oil, water and sand from deep hydrocarbon reservoir beds. 


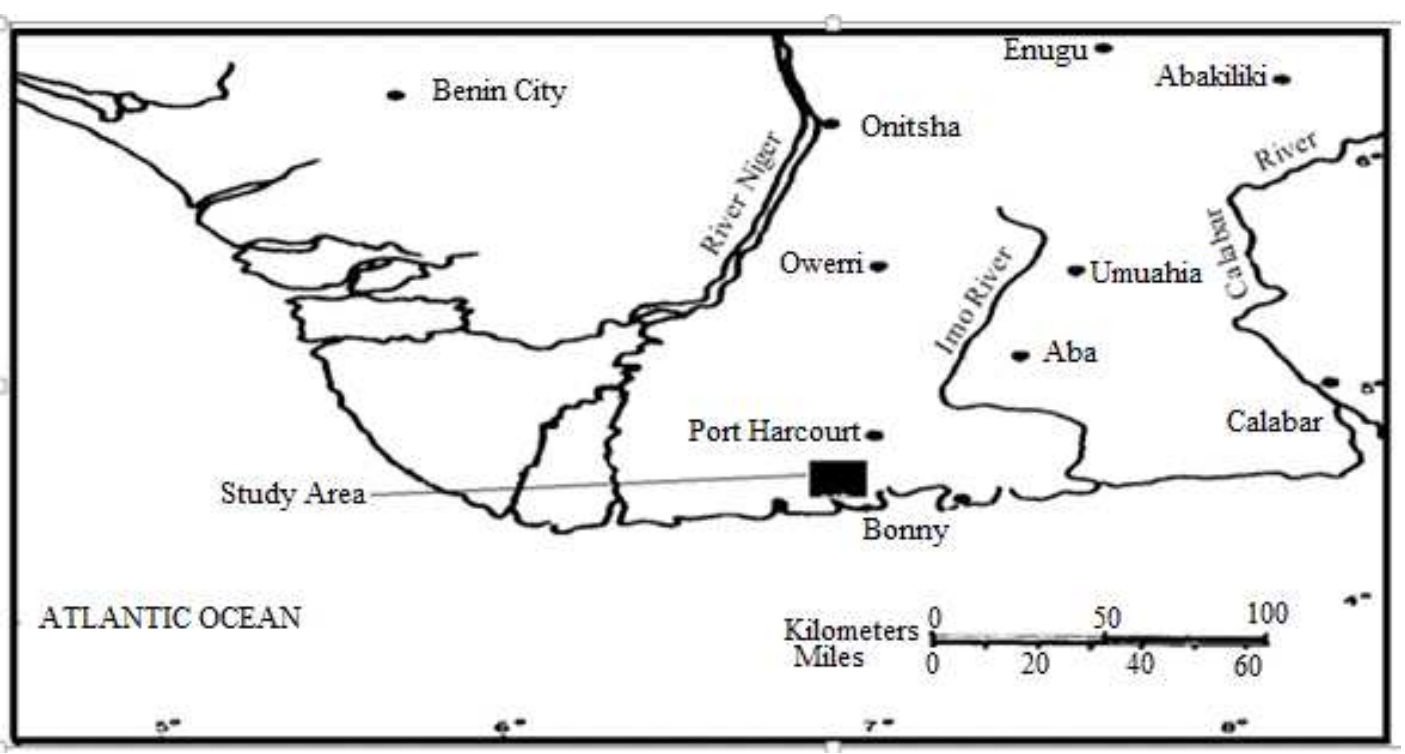

Fig. 1. Map of the Niger Delta region showing the study area

Since then, ground subsidence caused by hydrocarbon withdrawal have been reported by several authors for fields in different parts of the world. These are the Groningen gas field in Netherlands (Boot, 1973), Ekofisk oil field in Norway (Zaman et al., 1995), Strachan oil field in Canada (Valentine et al., 1999), Goose Creek oil field in Texas and Coasta Oriental oil field in Venezuela (Jenny, 2010). Generally, the authors were of the view that subsidence in each case was most probably triggered by hydrocarbon withdrawal, since there were no past history of tectonism in these fields.

The study area lies in the eastern Niger delta X-field (Fig. 1). The field has been into commercial production of hydrocarbons for the past twenty seven years with eighteen closely clustered oil producing wells. Seven wells are producing at their peaks at the present, while the remaining ones have either been abandoned or tertiary produced. The reservoir depths vary between 2,500 to a maximum of $4,000 \mathrm{~m}$. The field is a seismic and as such, there has been no reported case of any natural or anthropogenic induced seismic event prior to field development and production.

Recently, four wells in the field which were originally situated on dry land and the adjoining land areas have occasionally been flooded by seawater especially during high tide periods. This can not only be attributed to rise in sea water level due to global climate change, but also probably to hydrocarbon productioninduced surface subsidence in the field. The magnitude of this effect is small and as a consequence, it is often times unnoticed in the field. The environmental consequences include flooding of coastal and inland urban and rural areas, increasing vulnerability to salt water intrusion, contamination of shallow aquifers, cracking of infrastructures and damage to surface structures.

The present study aims at evaluating changes in time-lapse seismic attributes from inverted 4D post stack depth migrated seismic data. Changes in these attribute properties are associated with changes in fluid saturation and pore pressures and hence, compaction of the reservoir and ground subsidence could be speculated in the field.

\section{Theoretical Background}

Hydrocarbon production is associated with pore pressure, saturation and temperature changes in the reservoir. Changes in these reservoir properties affects seismic elastic properties considerably, such that changes in elastic reservoir properties over a time lapse are considered a function of changes in pore pressure and water saturation. The percentage change in water saturation is higher than the pressure change. As such, saturation changes are more likely to be detected than pressure changes on a seismic attribute slice.

Several mechanisms have been proposed to explain the origin of ground subsidence associated with hydrocarbon production. Considerable decline in reservoir pore pressure due to hydrocarbon withdrawal is implied as the primary cause (Biot, 1941; 1955; Gaia and Stefano, 2006; Gambolati and Teatini, 2015).

In a hydrocarbon reservoir, the overburden pressure $\left(P_{o v}\right)$ is supported mainly by the Fluid Pore pressure (FP) and the Grain (matrix) Pressure (GP) (Fig. 2). This relationship is expressed as:

$P_{o v}=F P+G P P_{o v}$ 


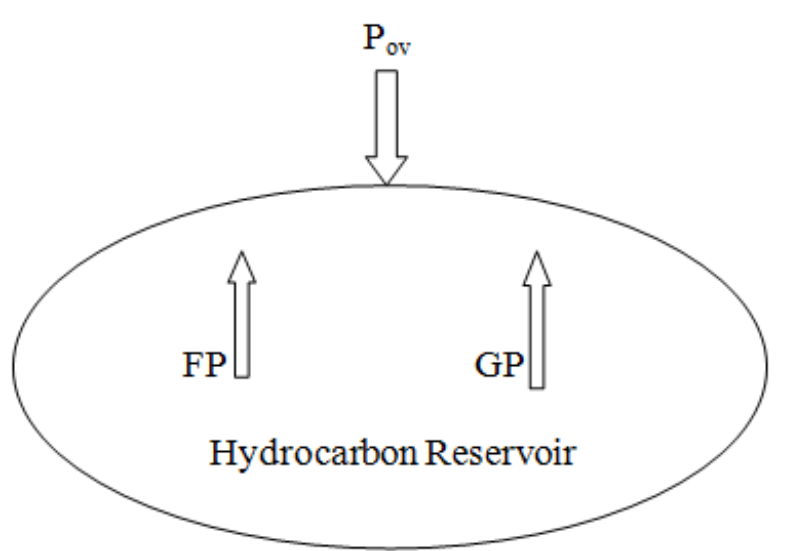

Fig. 2. Overburden supported by fluid pore and matrix pressures in a reservoir

But production of hydrocarbon from the reservoir is associated with pore pressure decline at a constant overburden pressure. As a consequence, the effective pressure $\left(P_{\text {eff }}\right)$ increases in both the reservoir matrix and the adjacent formations. This pressure difference is expressed by:

$$
P_{e f f}=P_{o v}-F P
$$

From Equation 2, it is evidently clear that the effective pressure increases with pore pressure decline in the reservoir for a constant overburden. The load on the reservoir is now borne by the rock matrix alone leading to increased grain-to-grain contacts and depletion of fluid volume. The effective pressure $P_{\text {eff }}$ is equal to the net compaction pressure $\left(P_{c}\right)$ on the reservoir matrix given by:

$$
P_{c}=P_{e f f}=P_{o v}-F P
$$

From Equation 2 and 3 it can be shown that the $P_{\text {eff }}$ is equal to $P_{c}$ as pore pressure declines in the reservoir.

Since the reservoir matrix is incompressible, the bulk volume of the reservoir is reduced due to pore and matrix volume decreases, while the area of the reservoir remains constant. Therefore, reservoir compacts (thickness decreases) causing subsidence of the overlying strata. The decrease in bulk volume is associated with a corresponding decrease in the reservoir compressibility and as a consequence, seismic acoustic properties such as density, velocity and hence, impedance increases within the reservoir.

By extracting and analyzing these reservoir rock/attribute properties from inverted seismic volume from two vintages, changes in these rock/attribute properties could be detected and correlated with changes in fluid saturation and pressure. This way, reservoir compaction and hence, ground subsidence could be speculated in the field.

\section{Geologic Setting of the Field}

The X-field is partly located on a large anticlinal structure that plunges slightly to the north east and bounded by growth faults striking NE and SW (Fig. 3). The reservoir is $140 \mathrm{ft}$ thick and consist of well sorted and fine-to-medium grained unconsolidated sands of the tertiary Niger delta Agbada Formation with excellent reservoir properties.

The reservoir is highly saturated with light crude $\left(25^{\circ} \mathrm{API}\right)$, has high oil/gas ratio and hydrostatically supported with an initial pressure of 2532 psi. Water is the main drive mechanism of hydrocarbon in the field.

\section{Materials and Methods}

Well and 4D seismic data sets from an X-field in the eastern Niger delta was used for this study. Three wells $\mathrm{A}, \mathrm{B}$ and $\mathrm{C}$ were considered for the study. Well $\mathrm{B}$ is the deepest with relevant log types and was used for evaluation and petrophysical modelling. The well log data comprising density, gamma ray, sonic and resistivity logs, were de-spiked using a median filter, after corrections for mud filtrate invasions, well bore wash outs and missing data (Fig. 4). Shear impedance, $V_{P} V_{S}$ ratio, acoustic impedance, Murho and Lambdarho pseudo logs were modeled from the available well log data using appropriate rock physics empirical relations (Castagna et al., 1985; Goodway et al., 1997).

These log-derived rock properties/attributes were analyzed over the reservoir interval in $3 \mathrm{D}$ cross plot space and by Gassmann's fluid substitution modeling. This was done primarily for the purposes of determining the sensitivity of changing reservoir saturations on rock/attribute properties due to hydrocarbon production.

The 4D seismic data is comprised of two 3D post stack depth migrated seismic data acquired in 1986 and 1999, respectively. The data set from the two vintages were independently inverted into acoustic impedance volumes using model-based inversion scheme. Neural network algorithm were subsequently used to extract petrophysical property volumes based on well log cross plot analysis. Pore pressure data were not available for this study hence, pore pressure effects were inferred from petrophysical analysis of reservoir rock properties over this time lapse.

\section{Presentation of Results}

A typical cross plot of acoustic impedance (Ip) Vs. Lamdarho $(\lambda \rho)$ color coded with Density $(\rho)$ as the third dimension (Fig. 5), showed data clusters separated into four distinct zones inferred to be gas, oil, brine and shale, respectively. Low values of $\mathrm{Ip}, \lambda \rho$ and $\rho$ are associated with gas and oil saturations, while higher values correspond to brine saturation and shale. 


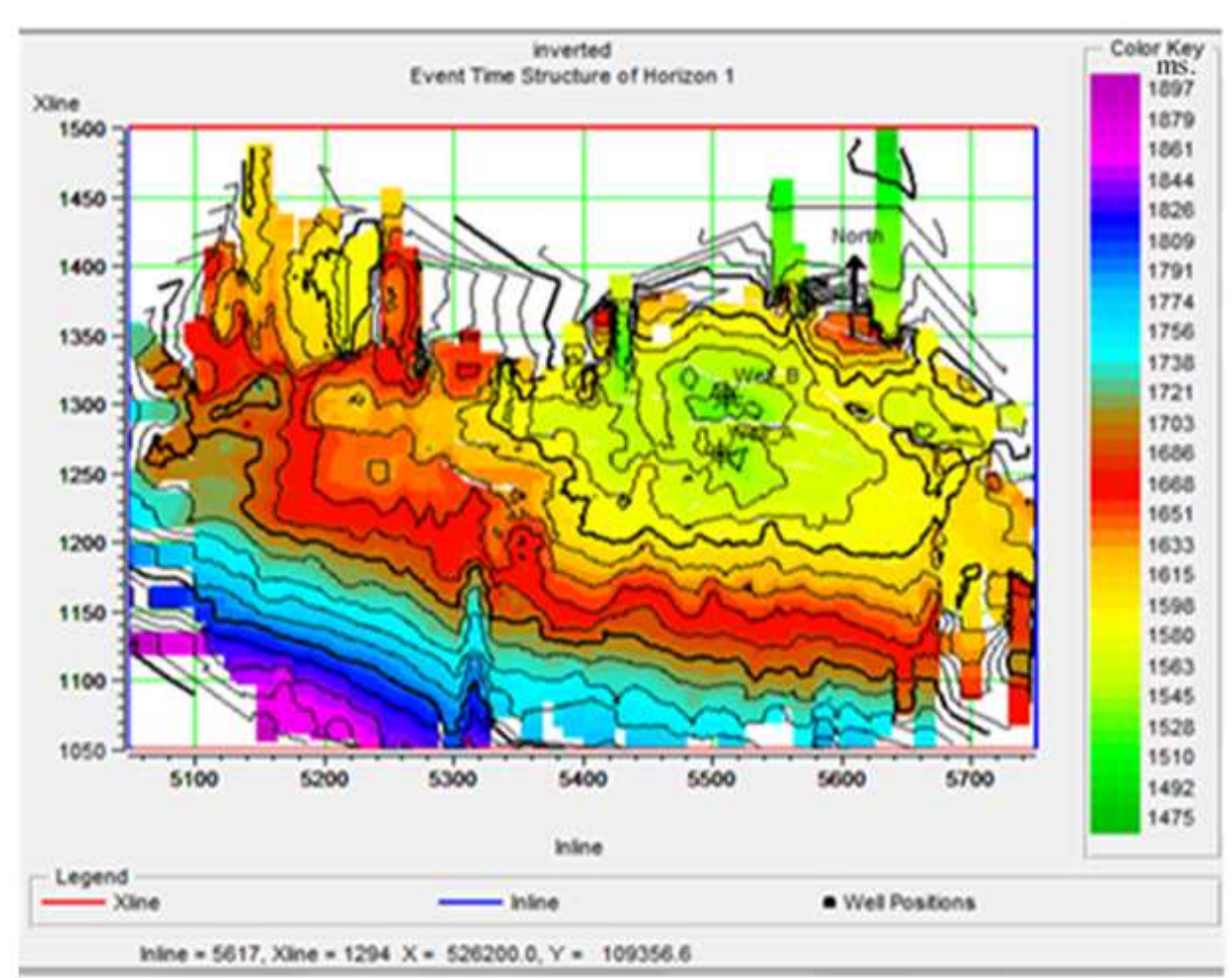

Fig. 3. Event time structure map of the field

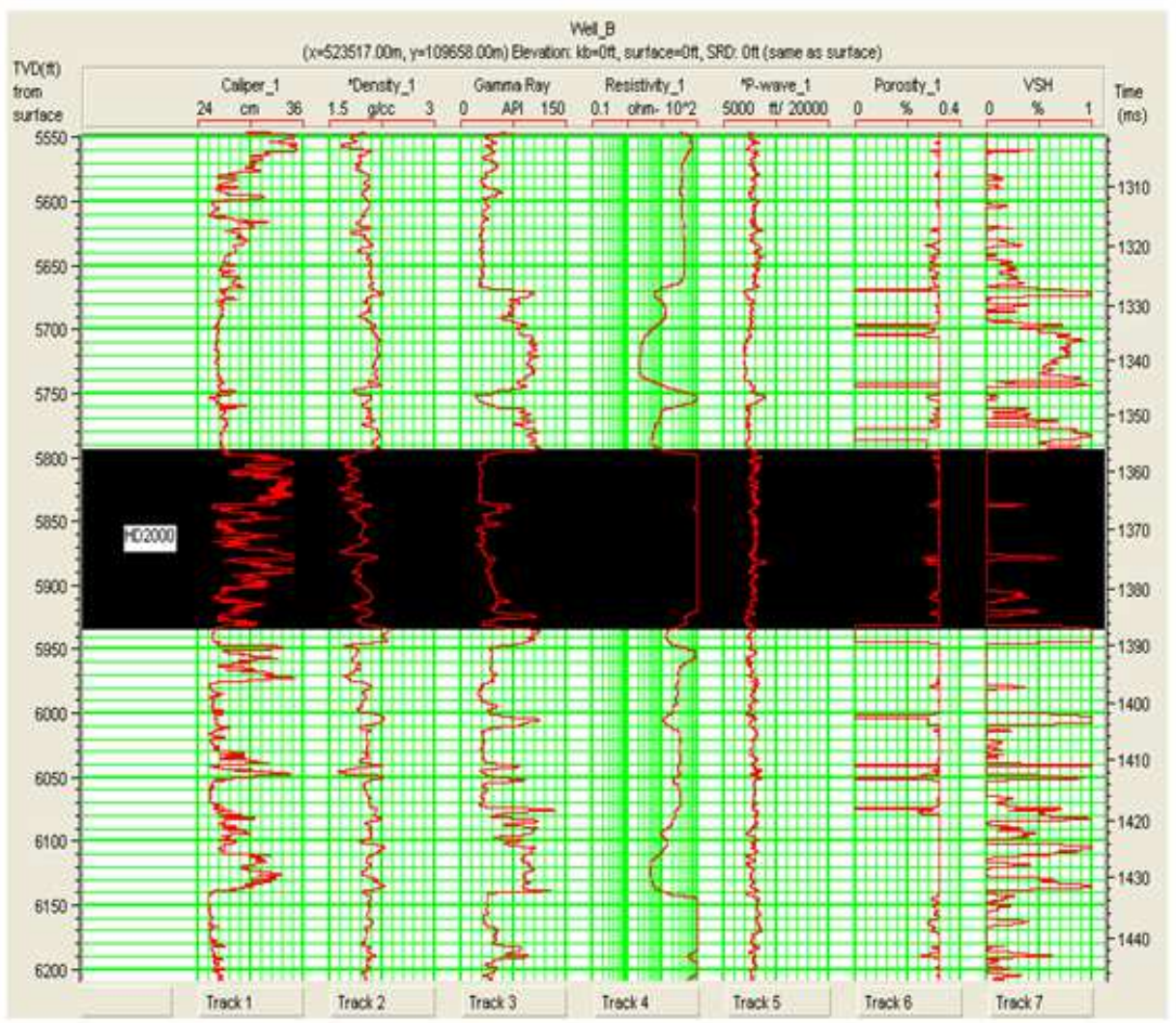

Fig. 4. Suites of well logs for well B showing the HD2000 Reservoir 


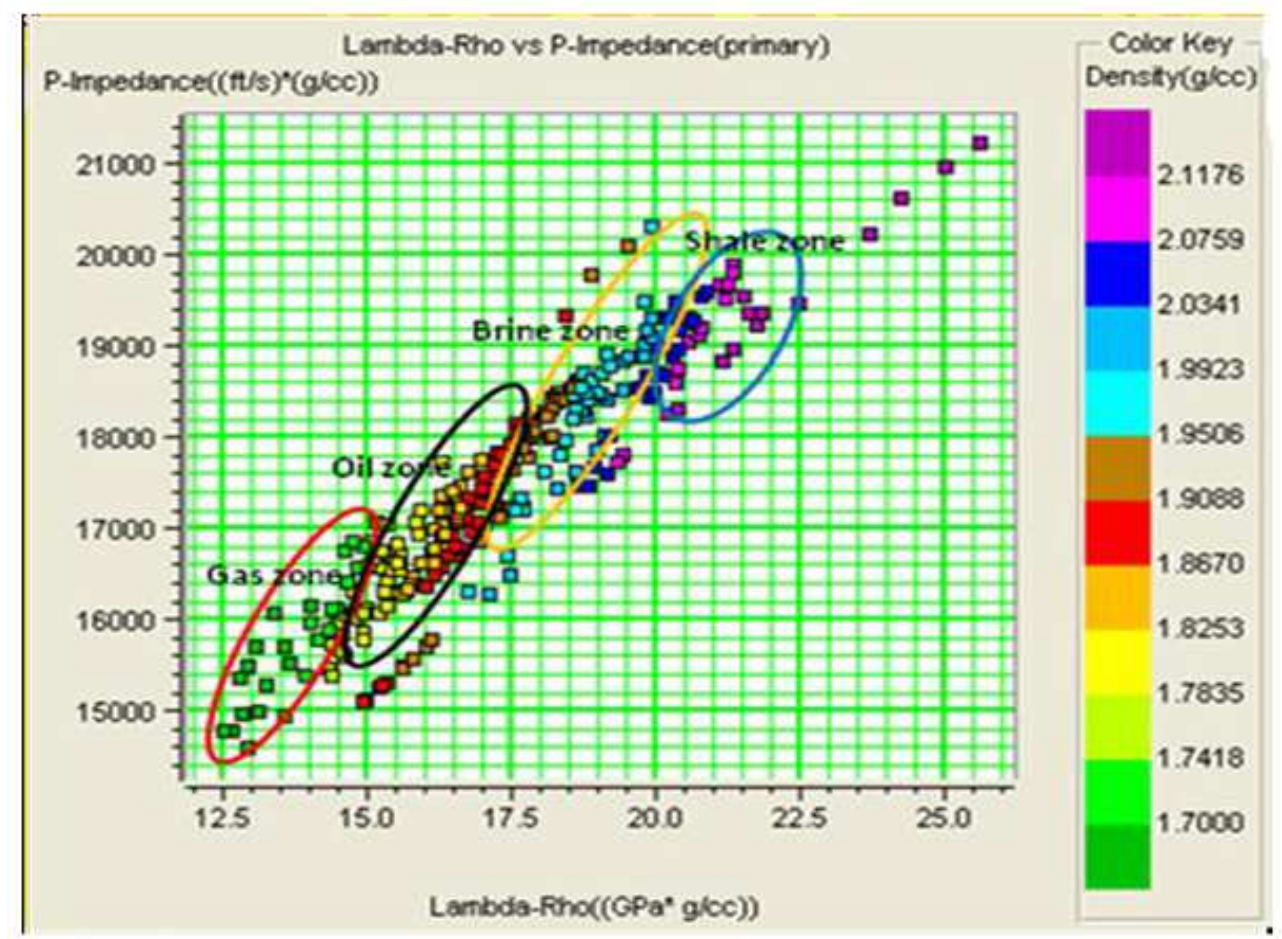

Fig. 5. Ip Vs. $\lambda \rho$ cross plot color coded with density

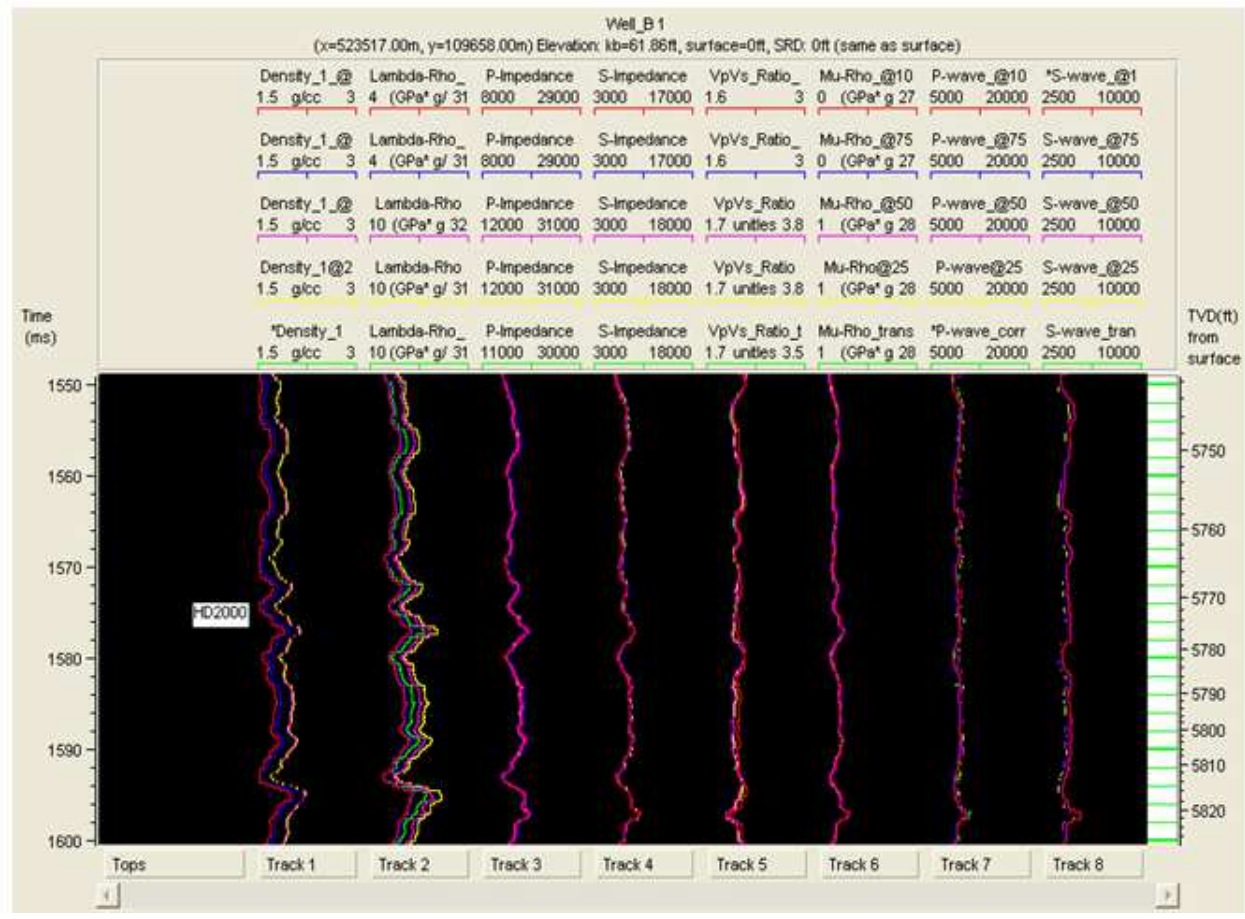

Fig. 6. Reservoir rock and attributes property response to varying oil-brine saturations

Gassmann's fluid substitution modeling for 25 to $100 \%$ oil and brine saturations over the reservoir interval showed heightened sensitivity to varying saturations by $\lambda \rho$ and $\rho$ than Ip (Fig. 6). Result of the modelling show distinct separations of $\rho, \lambda \rho$ and Ip curves (red and blue) for higher hydrocarbon saturation. At lower saturation, the $\lambda \rho$ curves are still distinguishable while the $\rho$ curves have merged and no observable Ip curve. 


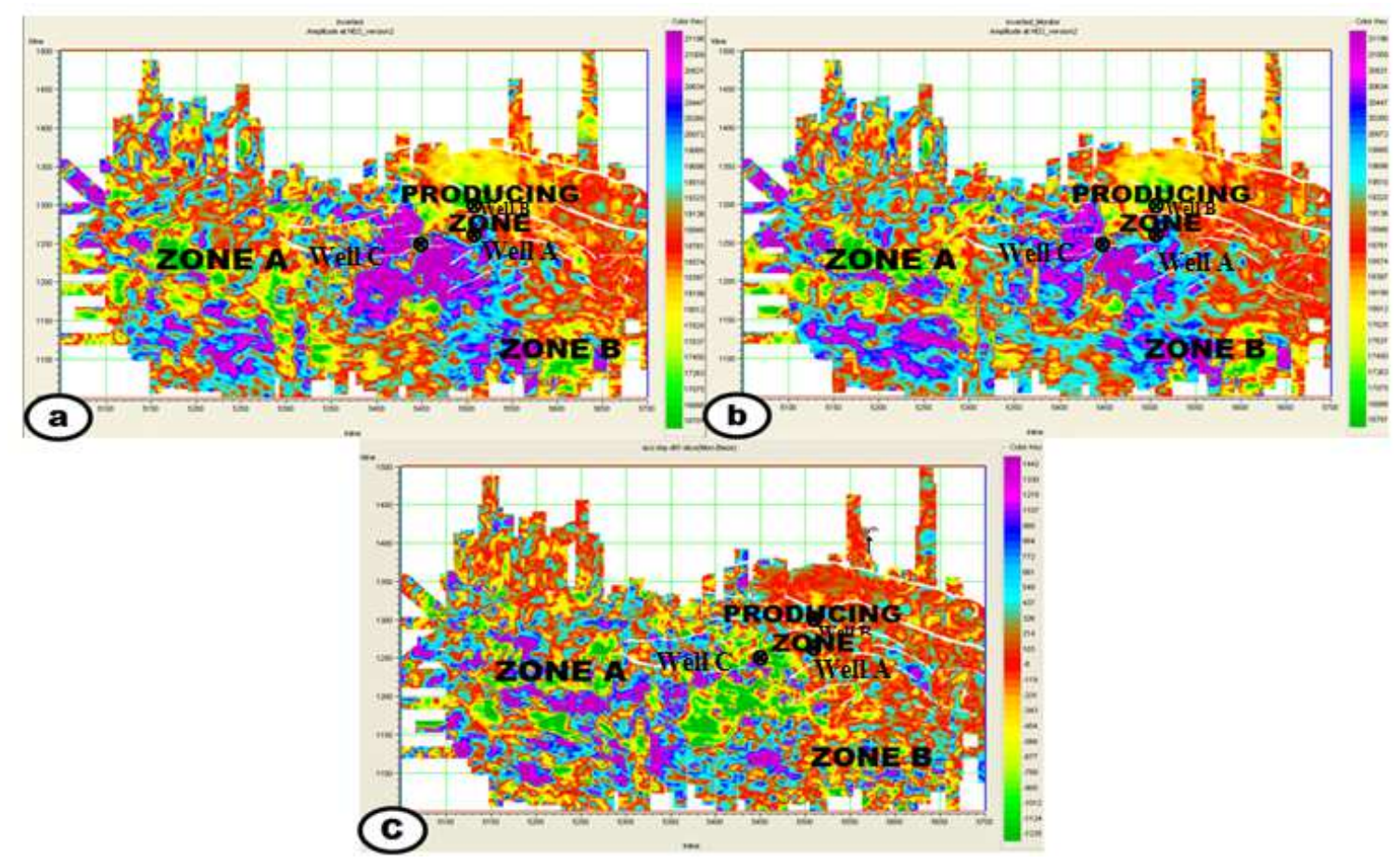

Fig. 7. Acoustic impedance horizon slices (a) base (b) Monitor (c) Difference slice

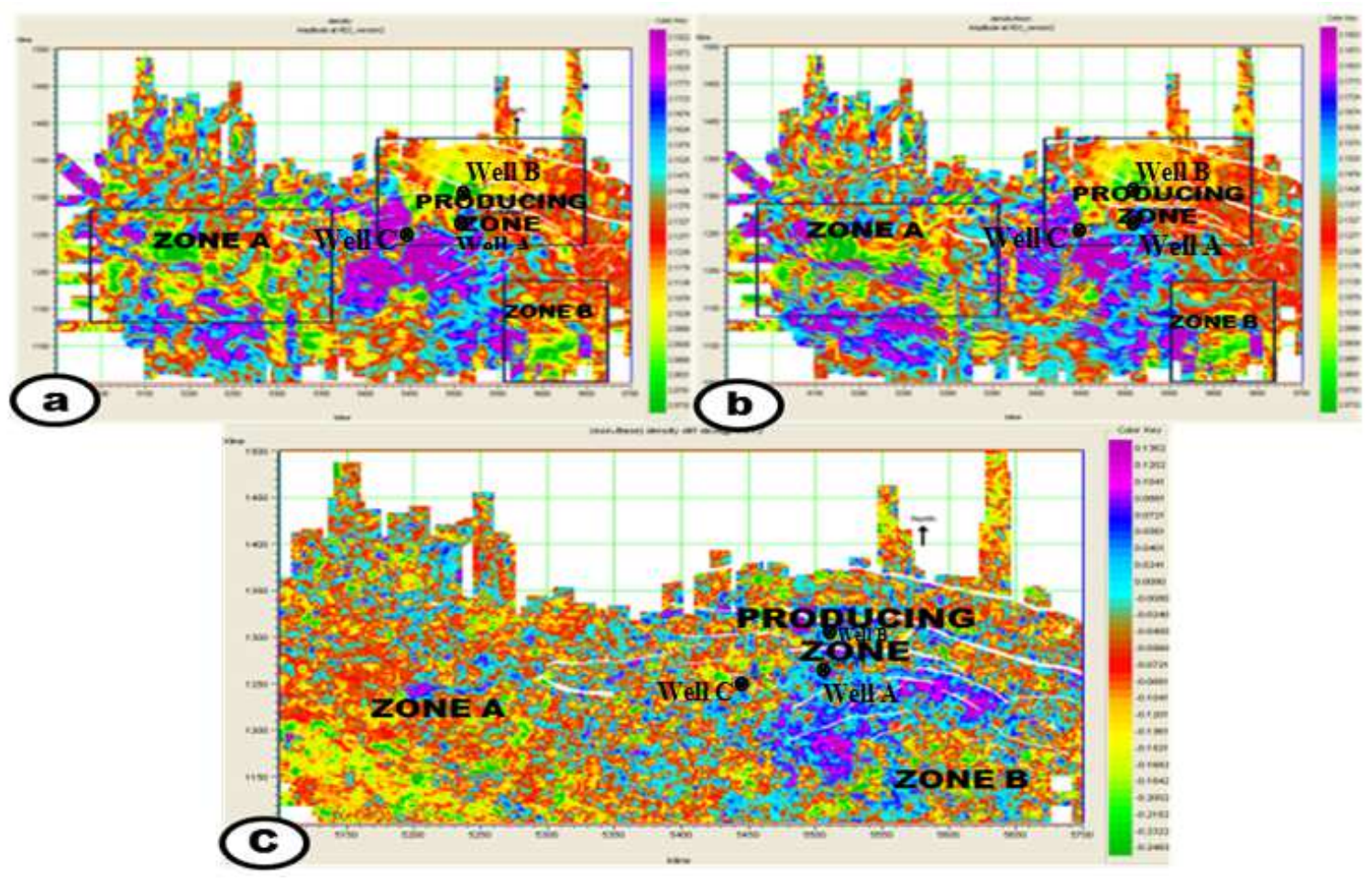

Fig. 8. Density horizon slices (a) Base (b) Monitor (c) Difference slice

From petrophysical analyses, it is evident that brine replacing hydrocarbon due to production will increase the specific values of these rock/attribute properties over the reservoir interval due to decreased reservoir compressibility. Subsequently, these reservoir properties and water saturation were extracted from inverted acoustic impedance volumes from the two vintages and compared along the same seismic horizon. 


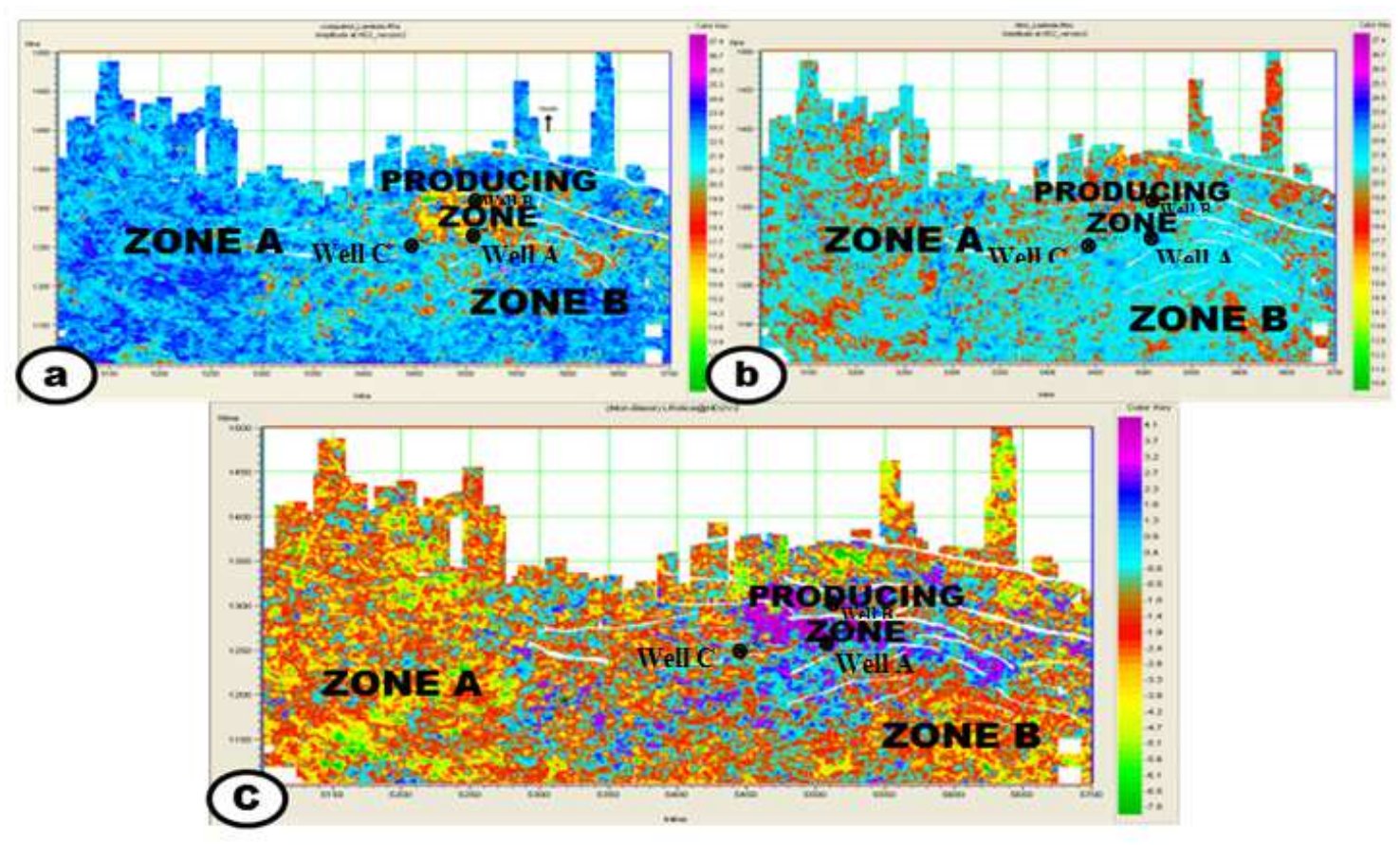

Fig. 9. Lambda-rho horizon slices (a) Base (b) Monitor (c) Difference slice

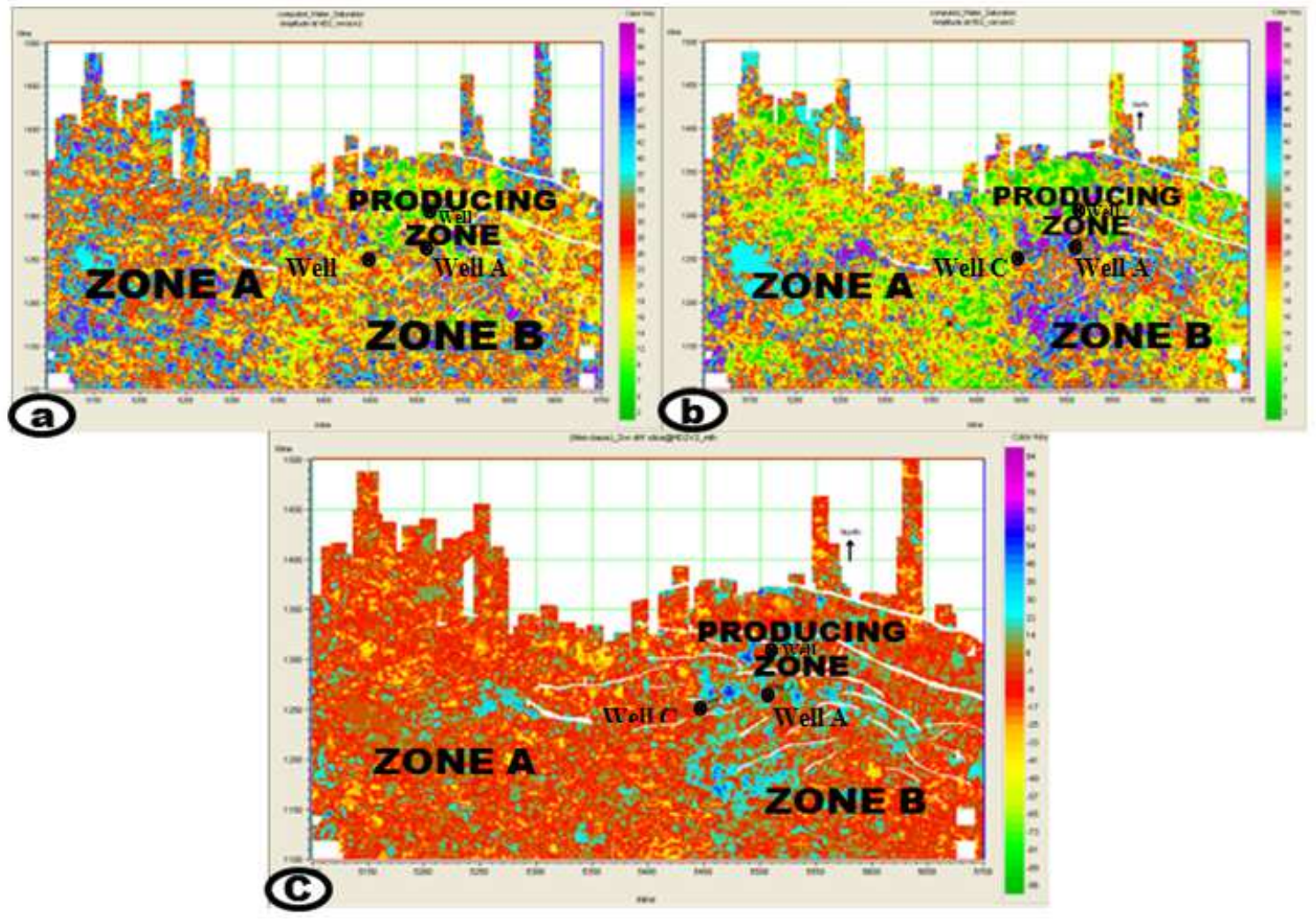

Fig. 10. Water saturation horizon slices (a) Base (b) Monitor (c) Difference slice

Results show that $\rho, \lambda \rho$, Ip and water saturation horizon slices from the base data delineated the well locations as zones of low rock property/attribute values, while the monitor horizon slices exhibited moderate rock 
property values in well $\mathrm{B}$ and higher values in wells $\mathrm{A}$ and $\mathrm{C}$ locations respectively. The difference horizon slices show well B lying on relatively low rock/attribute property zones, while wells $\mathrm{A}$ and $\mathrm{C}$ lie on high zones. Results show that while well B is still producing, wells $A$ and $C$ have probably watered out (Fig. 7-10). The insert (zones $\mathrm{A}$ and $\mathrm{B}$ ) in the figures are suspected bypassed hydrocarbon resources in the field.

\section{Discussion of Results}

Hydrocarbon production-induced subsidence has been investigated in a Niger delta X-field. Well log data from three wells (A, B and C) and 4D seismic data were used for the study. Petrophysical analyses of well and seismic data revealed that $\rho, \lambda \rho$ and Ip were sensitive to reservoir fluid saturation changes. Results show that fluid saturation changes due to hydrocarbon production increases the specific values of $\rho, \lambda \rho$ and Ip over the reservoir interval.

The monitor horizon slices show appreciable increases in values of $\rho, \lambda \rho$, Ip and water saturation properties compared to the base data. The $\rho, \lambda \rho$ and Ip and water saturation difference horizon slices indicate that well B is situated on relatively low amplitude zone, while wells $A$ and $C$ are situated on highs. Results show that while well $\mathrm{B}$ is still producing, wells $\mathrm{A}$ and $\mathrm{C}$ have probably watered out.

Differences in $\rho, \lambda \rho$ and Ip and water saturation between the two vintages are indications of pore pressure and pore fluid depletion in the reservoir. Pore pressure depletion for a constant overburden increases the effective stress (pressure) and the grain-to-grain contact of the reservoir matrix. Consequently, pore and matrix volume decreases, reservoir compacts, pre-existing faults are likely to be reactivated and seismicity is induced in the reservoir and adjoining formations.

Compaction reduces porosity, permeability and the compressibility of reservoir materials. Decrease in reservoir compressibility increases density, lambdarho, compressional velocity and acoustic impedance over the reservoir interval in the monitor horizon slice compared to base. These observations are indications that the reservoir may have compacted over time due to hydrocarbon production. The cumulative compaction of subsurface layers extends its effects to the ground surface, which therefore subsides.

This ground subsidence is suspected to be small and at the reservoir scale due to low initial reservoir porosity and the relatively large lateral dimension compared to the thickness of the reservoir. The amplitude is suspected to be very much less than three (3) on the Richter scale, which are hardly perceptible by human. The most visible effect of this in the field is the occasional flooding of existing wells situated on dry lands and adjoining land areas in the recent time during high tide periods, increasing vulnerability to salt water intrusion, contamination of shallow aquifers, cracking of infrastructures and damage to surface structures in the field.

\section{Conclusion}

Hydrocarbon production-induced subsidence has been inferred from the evaluation of reservoir rock/attribute property changes between two vintages. Petrophysical analysis of well log and seismic data show that $\lambda \rho, \rho$ and Ip exhibit significant changes in specific values for time varying reservoir fluid saturation and pore pressure conditions. Results show that these rock properties are relatively low around well $\mathrm{B}$, but higher around wells $\mathrm{A}$ and $\mathrm{C}$ over these time lapse. Examination of the difference data revealed that well $\mathrm{B}$ is still producing, while wells $\mathrm{A}$ and $\mathrm{C}$ have probably watered out.

These increases in values of $\lambda \rho, \rho$ and Ip between the time-lapse for a constant overburden stress, gives indications of pore pressure depletion and possible effective stress build up. This reduces the shear strength of the reservoir rock resulting in compaction and subsidence. The subsidence is suspected to be small and at the reservoir scale due to low initial reservoir porosity and relatively large lateral dimension compared to the thickness of the reservoir. This may have spread over an area extending beyond the field.

\section{Acknowledgement}

We express our appreciation to the HAMPSONRUSSELL Corporation and the SHELL PETROLEUM DEVELOPMENT COMPANY Port Harcourt, for their technical support, without which we would not have succeeded.

\section{Author's Contributions}

Chukwuemeka Ngozi Ehirim: Reviewed literature, processed data and discussed the results.

Tamunonengiyeofori Dagogo: Processed data, analyzed and presented results.

\section{Ethics}

This article is original and contains unpublished material. The corresponding author confirms that all of the other authors have read and approved the manuscript and no ethical issues involved.

\section{References}

Biot, M.A., 1941. A general theory of 3D consolidation. J. Applied Geophys., 12: 182-164.

Biot, M.A., 1955. Theory of elasticity and consolidation for a porous anisotropic solid. J. Applied Geophys., 26: 182-185. DOI: $10.1063 / 1.1721956$ 
Boot, R., 1973. Level control surveys in the groningen gas field. Verhandelingen Kon. Ned, Geol. Mijnbouwk. Gen., 28: 105-109.

Castagna, J.P., M.L. Batzle and R.L. Eastwood, 1985. Relationships between compressional-wave and shear-wave velocities in clastic silicate rocks. Geophysics, 50: 571-581. DOI: 10.1190/1.1441933

Chan, A.W. and M.D. Zoback, 2007. The role of hydrocarbon production on land subsidence and fault reactivation in the Louisiana coastal zone. J. Coastal Res., 23: 771-786. DOI: 10.2112/05-0553

Civasso, J.R., 1992. Mechanics of seismic instabilities induced by the recovery of hydrocarbons. Pure Applied Geophys., 139: 507-534. DOI: 10.1007/BF00879949

Dyer, B.C., R.H. Jones, J.F. Cowles, O. Barkverd and P.G. Folstad, 1999. Microseismic Survey of a North Sea Reservoir. World Oil.

Fuller, M., 1908. Summary of the controlling factors of artesian flows. US Geol. Surv. Bull., 319: 44-44.

Gaia, C. and M. Stefano, 2006. Numerical Simulation of Compaction and Subsidence Using ABAQUS. Proceedings the ABAQUS Users Conference, (AUC' 06), Milan-Italy, pp: 125-144.

Gambolati, G. and P. Teatini, 2015. Geomechanics of subsurface water withdrawal and injection. Water Resources Res., 51: 3922-3955. DOI: $10.1002 / 2014 \mathrm{WR} 016841$

Goodway, B., T. Chen and J. Downton, 1997. Improved AVO fluid detection and lithology discrimination using lame's petrophysical parameters. Proceedings CSEG Convention.
Hermansen, H., H.A. Landa, J.E. Sylte and L.K. Thomas, 2000. Experiences after 10 years of waterflooding the Ekofisk Field, Norway. J. Pet. Sci. Eng., 26: 11-18. DOI: 10.1016/S0920-4105(00)00016-4

Jenny, S., 2010. Moderate-to-large seismicity induced by hydrocarbon production. Lead. Edge, 29: 310-319. DOI: $10.1190 / 1.3353728$

Pratt, W.E. and W.D. Johnson, 1926. Local subsidence of the goose creek oil field. J. Geol. 34: 577-590.

Rutledge, J.T., W.S. Philips and B.K. Shuessler, 1998b. Reservoir characterization using oil-productioninduced microseismicity, Clinton County, Kentucky. Tectonophysics, 289: 129-152. DOI: 10.1016/S0040-1951(97)00312-0

Scott, W.P., T.R. James, S.H. Leigh and C.F.I. Michael, 2000. Induced micro-earthquake patterns in hydrocarbon and geothermal reservoirs.

Segall, P., 1989. Earthquakes triggered by fluid extraction. Geology, 17: 942-946.

DOI:

$10.1130 / 0091-$ 7613(1989)017<0942:ETBFE $>2.3 . C O ; 2$

Valentine, B., M. Azar and B. Sebastian, 1999. A model for induced seismicity caused by hydrocarbon production in the western Canada sedimentary basin. Can. J. Earth Sci., 36: 47-64. DOI: 10.1139/e98-080

Zaman, M.M. A. Abdulrahheem and J.C. Roegiers, 1995. Reservoir compaction and surface subsidence in the North Sea Ekofisk field. Elsevier Sci., 41: 373-419. DOI: 10.1016/S0376-7361(06)80055-5 